Research Article

\title{
Clean and Safe Healthcare Environment: Knowledge, Attitude, and Practice of Infection Prevention and Control among Health Workforce at North Showa Zone Oromiya Region
}

\author{
Kemal Jemal $\left(D,{ }^{1}\right.$ Ketema Gashaw, ${ }^{2}$ Tadele Kinati, ${ }^{1}$ Worku Bedada, ${ }^{3}$ and Belete Getahun ${ }^{4}$ \\ ${ }^{1}$ Salale University, College of Health Sciences, Department of Nursing, Fitche, Ethiopia \\ ${ }^{2}$ Salale University, College of Health Sciences, Department of Public Health, Fitche, Ethiopia \\ ${ }^{3}$ Adama Hospital Medical College, Adama, Ethiopia \\ ${ }^{4}$ Canadian Physicians for Aid and Relief, Addis Ababa, Ethiopia
}

Correspondence should be addressed to Kemal Jemal; olifanjemal@gmail.com

Received 21 April 2020; Revised 6 October 2020; Accepted 21 October 2020; Published 31 October 2020

Academic Editor: Andrea Piana

Copyright (C) 2020 Kemal Jemal et al. This is an open access article distributed under the Creative Commons Attribution License, which permits unrestricted use, distribution, and reproduction in any medium, provided the original work is properly cited.

Background. Infection prevention and control practice (IPCP) is essential for healthcare safety and quality service delivery. The Ethiopian government has already put in place programs and initiatives for clean and safe healthcare facilities. However, in the North Showa Zone of the Oromiya Region, the infection prevention and control practice level was not well understood. Therefore, this study aimed to assess the knowledge, attitude, and practice of infection prevention and control practice among the health workforce (HWF) in North Shoa healthcare facilities (NSHCFs) environment. Methods. Healthcare facility-based cross-sectional study design was employed. Structured and pretested self-administered questionnaires were distributed for 373 health workforce. Three hospitals and six health centers were randomly selected, and the study participants were selected by systematic sampling technique. Data were entered into Epi-data version 3.5.2 and then exported to SPSS version 23 for analysis. Multivariable logistic regression was performed to determine the associated factors with infection prevention practice, and a $p$ value of less than 0.05 was considered statistically significant. Results. A total of 361 (96.8\%) health workforce responded to self-administered questionnaires. About $55.70 \%$ of study participants had good knowledge, $59.3 \%$ of them had a positive attitude, and $46.8 \%$ had a good infection prevention practice. Age category of $20-29(\mathrm{AOR}=4.08,95 \%, \mathrm{CI}=(1.97,8.49))$, female participants $(\mathrm{AOR}=3.87,95 \%, \mathrm{CI}=(1.91$, $7.86)$ ), single participants $(\mathrm{AOR}=3.89,95 \%, \mathrm{CI}=(1.92,7.87))$, having greater than ten years of working experience $(\mathrm{AOR}=3.10$, $95 \% \mathrm{CI}=(1.19,8.10))$, positive attitude $(\mathrm{AOR}=10.07,95 \% \mathrm{CI}=(4.82,21.05))$, and availability of water at working area $(\mathrm{AOR}=2.27,95 \% \mathrm{CI}=(1.18,4.35))$ were significantly associated with good infection prevention practice. Conclusion. In this study, a significant number of health workers had low knowledge, negative attitudes, and poor infection prevention practices. Female participants, higher work experience, a positive attitude, and water availability in the healthcare facilities were positively associated with infection prevention and control practice. Healthcare facilities should be continued capacitating the health workforce on infection prevention and control measures and equipping health facilities with infection prevention materials.

\section{Introduction}

Healthcare-associated infections (HCAIs) are a serious problem in healthcare settings, common causes of morbidity and mortality among the health workforce. In healthcare settings, around 1.4 million people are affected globally due to a lack of clean and safe healthcare facilities, which is 2 to 20 times higher in low-resource countries [1-5]. Healthcare facility-acquired infections occur in both high- and lowincome countries due to poor healthcare cleanliness. In the USA, 1.7 million hospital-acquired infections contributed to 99,000 deaths each year, with annual costs of 25.0 to 31.5 billion dollars [6-8].

A study done in Nigeria found that $90 \%$ of healthcare workers (HCWs) were knowledgeable, $92.3 \%$ had a good attitude toward infection prevention, and 50.8\% had good 
infection prevention and control practice [9]. A study done in Kenya indicated that only $17.8 \%$ of the study participants had adequate knowledge of the basic elements of infection prevention standard precautions [10].

In Ethiopia, a study done in Bahir Dar city indicated that $84.5 \%$ of the study participants were knowledgeable, $55.6 \%$ had a positive attitude, and $54.2 \%$ had good infection prevention practices [11]. Similarly, a study done in Addis Ababa among healthcare workers revealed that $55.4 \%$, $83.3 \%$, and $66.1 \%$ of the study participants had good knowledge, positive attitude, and good infection prevention practices, respectively [12]. Another study from Wolaita Sodo found that $99.3 \%$ of healthcare workers had good knowledge of infection prevention, 93.4\% had a positive attitude toward infection prevention and control measures, and $60.5 \%$ of healthcare workers had good infection prevention and control practice [13].

Healthcare-associated infections can affect patients, patient families, healthcare workers, and supportive staff [14-16]. Accordingly, it can cause needless pain and suffering, long-term disability, excess death, prolong hospital admissions, and costly financial burden on the healthcare system [17-20]. Healthcare facilities' cleanliness is a significant predictor of the quality of healthcare and patient safety. Therefore, ensuring the facilities are comfortable and safe for patients, attendants, and staff $[21,22]$, in which healthcare providers are responsible for the healthcare facilities, creates an infection-free environment [23-25].

The Ethiopian government has taken initiatives that demand clean and safe healthcare facilities, standard precautions, and biohazard-free facilities [26]. However, most healthcare facilities are not clean; the image of an odorous, poorly organized institution with a filthy environment is common, particularly in rural healthcare facilities. There is not a clean and safe healthcare implementation due to a lack of supportive supervision. To date, there are limited continuous assessments concerning the safety and cleanliness of healthcare facilities in the North Showa Zone, Oromiya region. Therefore, this study aimed to determine the level of infection prevention and control practice and identify associated factors among the HWF in NSHCFs environment.

\section{Methods}

2.1. Study Design, Area, and Period. A facility-based crosssectional study was applied from January to February 2019 in North Showa Zone, Oromiya Region. Fiche is the zonal town and located at $112 \mathrm{~km}$ from Addis Ababa in the North direction. The zone has two general hospitals, two district hospitals, 63 health centers, 268 health posts, seven medium clinics, 54 lower clinics, one drug store, 25 drug vendors, and three rural drug vendors.

2.2. Study Population. Health workforces who have been working for more than six months in North Showa Zone healthcare facilities were included in this study. We collected data from the health workforce (nurses, physicians, midwifery, medical laboratory professionals, health officers, pharmacists, ophthalmologists, and psychiatry nurses). Students who were on clinical attachment for less than six months and the health workforce on annual leave during data collection were excluded from the study.

2.3. Sample Size and Sampling Technique. The total sample size for this study was 373 as estimated using Epi-info version 7 power of $80 \%$ with a $95 \%$ CI and a $5 \%$ margin of error, taking a proportion of $36.3 \%$ from the study done in West Arsi district [27], and considering a 5\% of nonresponse rate. From 67 healthcare facilities, three hospitals and six health centers were selected randomly. The total sample size was allocated proportionately to each facility based on the size of their health workforce. Again the allocated number, in turn, is proportionally assigned to each department. Eligible participants within the departments were selected by systematic sampling technique.

2.4. Data Collection Tools and Procedure. Data were collected using structured and pretested self-administered questionnaires. Two trained data collectors (diploma nurses) and a supervisor (bachelors) were involved in data collection. The questionnaires were adapted from the World Health Organization Infection Prevention and Control Assessment Framework tool and Ethiopian national guideline for the Clean and Safe Health Facilities Audit Tool for infection prevention and control practice components $[28,29]$. The questionnaire contains the sociodemographic factors, infection prevention practice, knowledge, and attitude toward infection prevention.

Knowledge and attitude toward infection prevention and control practices were measured using ten questions which are "yes or no" for knowledge and agreed or disagreed for attitude; each correct answer "yes" or "agree" scored " 1 " and "no" or "disagree" scored " 0 " point for knowledge and attitude, respectively.

The outcomes of knowledge and attitude cut-off points were scored of eight and above $(\geq 80 \%)$. A score greater than $80 \%$ was considered good knowledge and a positive attitude, and that less than $80 \%$ was considered poor knowledge and a negative attitude toward infection prevention and control practices [30, 31].

Infection prevention and control practice was measured using twelve questions (yes/no). Each correct answer scored five-point, and if not, zero. The outcome was calculated using the mean score as a cut-off point. A score greater than the mean was considered good infection prevention and control practice, otherwise, poor practice [28].

2.5. Data Processing and Analysis. Data were coded, edited, and entered into Epi-data version 3.5.2 and transported to SPSS version 23 for further analyses. The descriptive data analysis was done and presented as frequency, summary statistics, graph, and table. Bivariate and multiple variable logistic regressions were performed to identify associated factors. Both crude and adjusted odds ratios with $95 \%$ 
confidence interval were computed, and statistical significance was declared at $p$ value $\leq 0.05$.

2.6. Ethical Consideration. Ethical clearance was obtained from the Salale University Ethical Review Committee. Written permission was obtained from the North Showa zonal health bureau and each healthcare facility. Written informed consent was obtained from each study participant. To ensure the confidentiality of respondents, their names were excluded from the questionnaire.

\section{Results}

In this study, a total of 361 respondents were included, with a $96.8 \%$ response rate. More than three-fourths of the study participants have participated from the hospitals. Respondents' age range was from 20 to 42 years old, with a mean age of 29.07 ( \pm standard deviation $=3.96)$. The higher proportion of 231 (64\%) was in the age range of 20 to 29 . Most study participants were male (66.8\%), married (63.3\%), BSc/MD (70.7\%), and nurses (43.5\%) that participated from hospitals. On the other hand, the salaries of the majority of participants in the health centers were between 1,080 and 4,999 Ethiopian Birr and had less than five years of experience (Table 1).

Two-thirds (238 (65.9\%)) of the respondents were aware of safe injection guidelines, and only $30.8 \%$ and $26.1 \%$ had taken the training on safe injection from health centers and hospitals, respectively. More than one-third (134 (37.1\%)) of the respondents had received training on handwashing practices, 34 (43.6) from health centers, and 100 (35.3) from hospitals. Three-seventh $(42.7 \%)$ of the respondents had reported the availability of color-coded liner bags for waste segregation in their working environment. More than half $(55.1 \%)$ and $69.8 \%$ of the respondents mentioned that a dust bin and adequate safety box were accessible in their working area, respectively. Merely, $47.4 \%$ of respondents had reported that health facilities had an active infection prevention and control committee (Table 2).

\subsection{Knowledge of the Health Workforce to Infection Prevention} and Control Practice. The overall knowledge of health workforce for infection prevention and control practice was $55.7 \%$ (210) with $95 \% \mathrm{CI}=(51.0$ to 60.9$)$ that had reported good knowledge of infection prevention and control practice, and $160(44.3 \%)$ of the respondents had reported poor knowledge of infection prevention and control practice (Figure 1).

More than three-fourths of the study participants were aware of the availability of infection prevention and control policies and guidelines for healthcare workers. About 327 (90.6\%) of the health workforce had known personal protective equipment to minimize healthcare-associated infections. More than half of the study participants had known that nosocomial infections could be transmitted through blood and body fluid contamination (54.6\%) and precautions of safe disposal for needle syringes and any sharp wastes $(57.3 \%)$. Two-thirds of the study participants knew the procedure of hand washing correctly (Table 3 ).
3.2. Attitude toward Infection Prevention and Control Practice among the Health Workforce. The majority of the study participants had reported a positive attitude toward infection prevention, and control practice was $59.3 \%$ (214) with $95 \% \mathrm{CI}=(53.7$ to 64.3$)$. In contrast, two-fifths of the health workforce had reported a negative attitude toward infection prevention and control practices (Figure 2).

Most of the study participants agreed that following standard operation procedures decreases the risk of contamination (70.1\%), using personal protective equipment decreases HCAIs (73.4\%), and using biohazard material is better for waste management (69.5\%). More than three-fifths of the study participants agreed that recapping needle is the cause for needle prick injury in the healthcare facilities. The majority $(287(79.5 \%))$ of the health workforce agreed to maintain ventilation in the ward or room by opening windows and doors to decrease infection transitions (Table 4).

\subsection{Infection Prevention and Control Practice among the} Health Workforce. Overall, less than half (169 (46.8\%) with $95 \% \mathrm{CI}=(41.8$ to 52.1$))$ of the health workforce had reported good infection prevention and control practices, whereas $192(53.2 \%)$ of the health workforce had reported poor infection prevention and control practices (Figure 3).

\subsection{Factors Associated with Infection Prevention Practices.} In the bivariable logistic regression analysis, the age category of 20 to 29 , single participants, educational status of BSC/ $\mathrm{MD}$ and MSC/specialty, female participants, nurse professionals, midwives and medical laboratory professions, good knowledge, and positive attitude were significantly associated with good infection prevention practice. Similarly, accessibility of dust bin, training on safe injection, and availability of water source in the working area were variables significantly associated with good infection prevention practice; whereas having good knowledge, accessible dustbins, and having training on injection safety were adjusted in multivariable logistic regression (Table 5).

In the multiple variables logistic regression analysis, the age range of 20 to 29 was four times more likely to practice infection prevention than older age $[\mathrm{AOR}=4.08,95 \%$, $\mathrm{CI}=(1.97,8.49)]$. Female participants were four times more likely to practice infection prevention than male participants $[\mathrm{AOR}=3.87,95 \%, \mathrm{CI}=(1.91,7.86)]$. The odds of being single were four times more likely to practice infection prevention and control than being married $[\mathrm{AOR}=3.89,95 \%$, $\mathrm{CI}=(1.92,7.87)]$. Nurses, midwives, and medical laboratory professionals were increased by $2 \%, 4 \%$, and $5 \%$ of infection prevention and control practice than health officers and other healthcare professionals. Those who have greater than or equal to ten years of work experience were three times more likely to practice infection prevention and control than those with less than five years of work experience $[\mathrm{AOR}=3.10,95 \% \mathrm{CI}=(1.19,8.10)]$. The study participants who have a positive attitude toward infection prevention and control practice were ten times more likely than a negative attitude $[\mathrm{AOR}=10.07,95 \% \mathrm{CI}=(4.82,21.05)]$. There was 
TABle 1: Sociodemographic and economic characteristics among the HWF in NSHCFs environment, Oromiya region, Ethiopia, from January to February $2019(n=361)$.

\begin{tabular}{|c|c|c|c|}
\hline \multirow{3}{*}{ Variables } & \multicolumn{3}{|c|}{ No. $(\%)$} \\
\hline & \multirow{2}{*}{ Total } & \multicolumn{2}{|c|}{ Healthcare facilities } \\
\hline & & Health center & Hospitals \\
\hline Overall & $361(100)$ & $78(21.6)$ & $283(78.4)$ \\
\hline \multicolumn{4}{|l|}{ Age } \\
\hline $20-29$ & $231(64)$ & $42(53.8)$ & $189(66.8)$ \\
\hline $30-42$ & $130(36)$ & $36(46.2)$ & $94(33.2)$ \\
\hline \multicolumn{4}{|l|}{ Sex } \\
\hline Male & $244(67.6)$ & $55(70.5)$ & $189(66.8)$ \\
\hline Female & $117(32.4)$ & $23(29.5)$ & $94(33.2)$ \\
\hline \multicolumn{4}{|l|}{ Marital status } \\
\hline Single & $131(36.3)$ & $27(34.6)$ & $104(36.7)$ \\
\hline Married & $230(63.7)$ & $51(65.4)$ & $179(63.3)$ \\
\hline \multicolumn{4}{|l|}{ Educational status } \\
\hline Diploma & $83(23)$ & $21(26.9)$ & $62(21.9)$ \\
\hline $\mathrm{BSc} / \mathrm{MD}$ & 249 (69) & $49(62.8)$ & $200(70.7)$ \\
\hline MSc/specialty & $29(8)$ & $8(10.3)$ & $21(7.4)$ \\
\hline \multicolumn{4}{|l|}{ Profession } \\
\hline Nurses & $159(44)$ & $36(46.2)$ & $123(43.5)$ \\
\hline Physicians & $55(15.2)$ & 0 & $55(19.4)$ \\
\hline Midwives & $43(11.9)$ & $11(14.1)$ & $32(11.3)$ \\
\hline MLS & $59(16.3)$ & $14(17.9)$ & $45(15.9)$ \\
\hline Health officer & $27(7.5)$ & $12(15.4)$ & $15(5.3)$ \\
\hline Others* & $18(5.1)$ & $5(6.4)$ & $13(4.6)$ \\
\hline \multicolumn{4}{|l|}{ Monthly salary } \\
\hline 1,080 to 4,999 & $229(63.4)$ & $46(59.0)$ & $183(64.7)$ \\
\hline 5,000 to 10,058 & $132(36.6)$ & $32(41.0)$ & $100(35.3)$ \\
\hline \multicolumn{4}{|l|}{ Year of experience } \\
\hline$<5$ & $210(58.2)$ & $38(48.7)$ & $172(60.8)$ \\
\hline $5-9$ & $107(29.6)$ & $29(37.2)$ & $78(27.6)$ \\
\hline$\geq 10$ & $44(12.2)$ & $11(14.1)$ & $33(11.6)$ \\
\hline
\end{tabular}

*Pharmacy, ophthalmologic nurse, and psychiatry nurse.

TABLE 2: Variables related to infection prevention and control practice among the HWF in NSHCFs environment, Oromiya region, Ethiopia, from January to February $2019(n=361)$.

\begin{tabular}{|c|c|c|c|}
\hline \multirow{3}{*}{ Variables } & \multicolumn{3}{|c|}{ No. $(\%)$} \\
\hline & \multirow{2}{*}{ Total } & \multicolumn{2}{|c|}{ Healthcare facilities } \\
\hline & & Health center & Hospital \\
\hline Overall & $361(100)$ & $78(21.6)$ & $283(78.4)$ \\
\hline \multicolumn{4}{|c|}{ Aware safe injection guidelines } \\
\hline Yes & $238(65.9)$ & $57(73.1)$ & $181(64.0)$ \\
\hline No & $123(34.1)$ & $21(26.9)$ & $102(36.0)$ \\
\hline \multicolumn{4}{|c|}{ Receives training on safe injection } \\
\hline Yes & $98(27.1)$ & $24(30.8)$ & $74(26.1)$ \\
\hline No & $263(72.9)$ & $54(69.2)$ & $209(73.9)$ \\
\hline \multicolumn{4}{|c|}{ Aware handwashing guidelines } \\
\hline Yes & $243(67.3)$ & $54(69.2)$ & $189(66.8)$ \\
\hline No & $118(32.7)$ & $24(30.8)$ & $94(33.2)$ \\
\hline \multicolumn{4}{|c|}{ Receive training on handwashing } \\
\hline Yes & $134(37.1)$ & $34(43.6)$ & $100(35.3)$ \\
\hline No & $227(62.9)$ & $44(56.4)$ & $183(64.7)$ \\
\hline \multicolumn{4}{|c|}{ Running water in working order } \\
\hline Yes & $113(31.3)$ & $26(33.3)$ & $87(30.7)$ \\
\hline No & $248(68.7)$ & $52(66.6)$ & $196(69.3)$ \\
\hline Training $\mathrm{c}$ & ste segregati & & \\
\hline
\end{tabular}

TABle 2: Continued.

\begin{tabular}{lccr}
\hline \multicolumn{4}{c}{ No. (\%) } \\
Variables & Total & \multicolumn{2}{c}{ Healthcare facilities } \\
& & Health center & Hospital \\
\hline Yes & $85(23.5)$ & $16(20.5)$ & $214(75.6)$ \\
No & $276(76.5)$ & $62(79.5)$ & $69(24.4)$ \\
Color-coded liner bags in HCFs & & \\
Yes & $154(42.7)$ & $35(44.9)$ & $119(42.0)$ \\
No & $207(57.3)$ & $43(55.1)$ & $164(58.0)$ \\
Dust bins accessible in HCFs & & $150(53.0)$ \\
Yes & $199(55.1)$ & $49(62.8)$ & $133(47.0)$ \\
No & $162(44.9)$ & $29(37.2)$ \\
Adequate safety box in HCFs & & \\
Yes & $252(69.8)$ & $51(65.4)$ & $201(71.0)$ \\
No & $109(30.2)$ & $27(34.6)$ & $82(29.0)$ \\
Health facilities have an active infection control committee \\
Yes & $171(47.4)$ & $40(51.3)$ & $131(46.3)$ \\
No & $190(52.6)$ & $38(48.7)$ & $152(53.7)$ \\
\hline \multicolumn{4}{c}{}
\end{tabular}

Knowledge of infection prevention and control practice

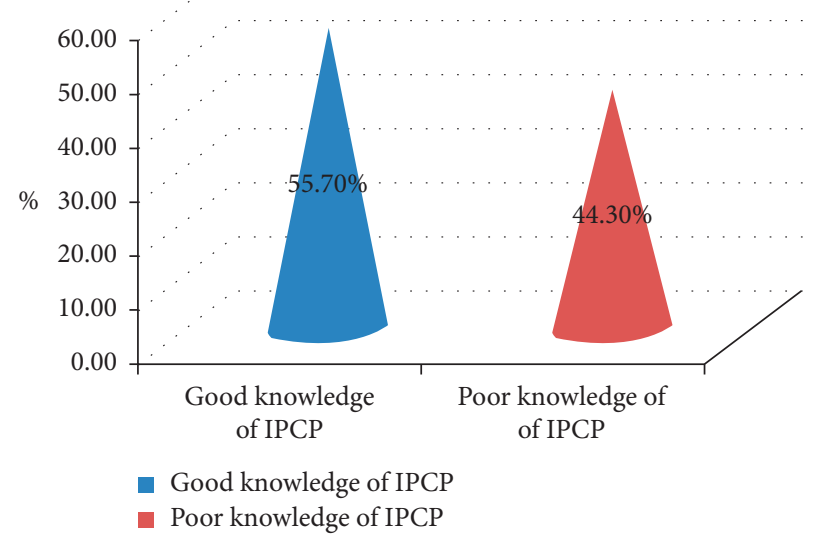

FIGURE 1: Knowledge of infection prevention and control practices among the HWF in NSHCFs environment, Oromiya region, Ethiopia, from January to February $2019(n=361)$.

also a significant association between the availability of water in the work area and infection prevention and control practices $[\mathrm{AOR}=2.27,95 \% \mathrm{CI}=(1.18,4.35)]$ (Table 5).

\section{Discussion}

We set out to assess infection prevention and control practices among the healthcare facility workforce to better understand the possible area for improving infection prevention and control practice. We found that 169 (46.8\%) of the respondents had reported good infection prevention and control practice. This result is in line with the study done in Mekelle, which found that $42.9 \%$ of the study participants had reported good infection prevention and control practice [32]. This finding is higher than that of the study conducted in the West Arsi district, which reported that $36.3 \%$ of healthcare workers had good infection prevention and control practices [27]. On the other hand, this result is lower 
TABLE 3: Knowledge of HWF about infection prevention and control practice in NSHCFs environment, Oromiya region, Ethiopia, from January to February $2019(n=361)$.

\begin{tabular}{|c|c|c|}
\hline Variables & Frequency & Percentage \\
\hline \multicolumn{3}{|c|}{ Are you aware of the manual listing of the infection prevention and control policies and guidelines for healthcare workers? } \\
\hline Yes & 285 & 78.9 \\
\hline No & 76 & 21.1 \\
\hline \multicolumn{3}{|c|}{ Do you know disinfection prevents hospital-acquired infection? } \\
\hline Yes & 305 & 84.5 \\
\hline No & 56 & 15.5 \\
\hline \multicolumn{3}{|c|}{ Do you know antiseptic and sterilization techniques prevent hospital-acquired infection? } \\
\hline Yes & 290 & 80.3 \\
\hline No & 71 & 19.7 \\
\hline \multicolumn{3}{|c|}{ Do you know personal protective equipment (mask, glove, and so on) minimizes HCAIs? } \\
\hline Yes & 327 & 90.6 \\
\hline No & 34 & 9.4 \\
\hline \multicolumn{3}{|c|}{ Do you know the proper handling of working equipment decreases the risk of contamination? } \\
\hline Yes & 309 & 85.6 \\
\hline No & 52 & 14.4 \\
\hline \multicolumn{3}{|c|}{ Do you know the precautions of safe disposal for needle syringes and any sharp wastes? } \\
\hline Yes & 207 & 57.3 \\
\hline No & 154 & 42.7 \\
\hline \multicolumn{3}{|c|}{ Do you know the procedure of hand washing correctly? } \\
\hline Yes & 237 & 65.7 \\
\hline No & 124 & 34.3 \\
\hline \multicolumn{3}{|c|}{ Do you know the effectiveness of handwashing in preventing HCAIs? } \\
\hline Yes & 260 & 72.0 \\
\hline No & 101 & 28.0 \\
\hline \multicolumn{3}{|c|}{ Do you know when to perform handwashing? } \\
\hline Yes & 240 & 66.5 \\
\hline No & 121 & 33.5 \\
\hline \multicolumn{3}{|c|}{ Do you know nosocomial infections can be transmitted through blood and body fluid contamination? } \\
\hline Yes & 197 & 54.6 \\
\hline No & 164 & 45.4 \\
\hline
\end{tabular}

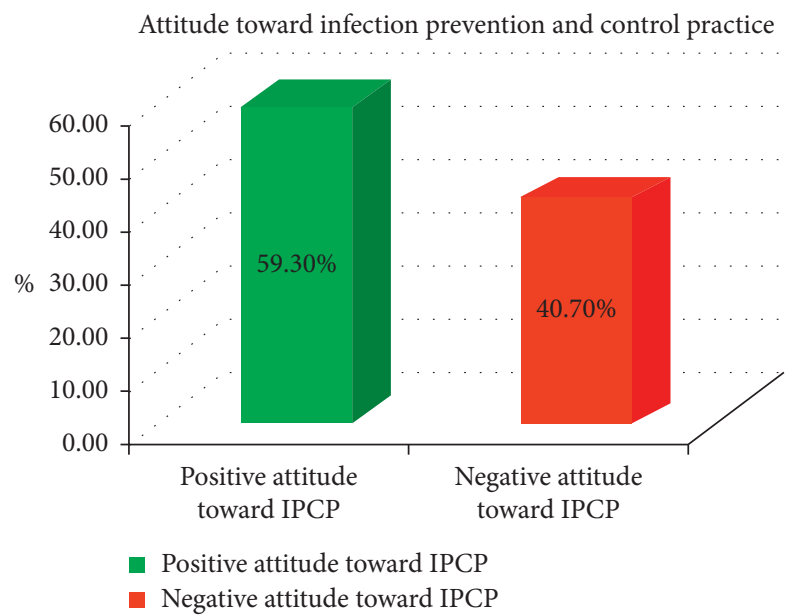

FIGURE 2: Attitude toward infection prevention and control practices among the HWF in NSHCFs environment, Oromiya region, Ethiopia, from January to February $2019(n=361)$.

than the results of studies in Addis Ababa health facilities (66.1\%) and Debre Markos Referral Hospital (57.3\%) $[12,33]$. The difference might be related to the level and location of these facilities.

In our study, $55.7 \%$ of the respondents had reported good knowledge of infection prevention and control practice, which is similar to the studies conducted in Addis
Ababa (55.4\%) and West Arsi (53.7\%) [27, 34]. This finding is higher than that of the study done in Amhara Regional State Referral Hospitals (40.7\%) [35]. Conversely, this study is low when compared with the results of studies reported in Bahir Dar city (84.5\%) [36] and Dessie Referral Hospital (95.19\%) [37]. The difference might be attributed to training opportunities. 
TABLE 4: Attitude toward infection prevention and control practice among the HWF in NSHCFs environment, Oromiya region, Ethiopia, from January to February $2019(n=361)$.

\begin{tabular}{|c|c|c|}
\hline Variables & Frequency & Percentage \\
\hline \multicolumn{3}{|c|}{ Do you believe that following standard operation procedures decreases the risk of contamination? } \\
\hline Agree & 253 & 70.1 \\
\hline Disagree & 108 & 29.9 \\
\hline \multicolumn{3}{|c|}{ Do you think ventilating the ward by opening windows and doors decreases infection transitions? } \\
\hline Agree & 287 & 79.5 \\
\hline Disagree & 74 & 20.5 \\
\hline \multicolumn{3}{|c|}{ Do you think using personal protective equipment (PPE) decreases HCAIs? } \\
\hline Agree & 265 & 73.4 \\
\hline Disagree & 96 & 26.6 \\
\hline \multicolumn{3}{|c|}{ Do you believe washing hands before and after contact with patients is important? } \\
\hline Agree & 286 & 79.2 \\
\hline Disagree & 75 & 20.8 \\
\hline \multicolumn{3}{|c|}{ Do you agree that hospital facilities can be the source of infection in the absence of universal precaution? } \\
\hline Agree & 260 & 72.0 \\
\hline Disagree & 101 & 28.0 \\
\hline \multicolumn{3}{|c|}{ Do you think separating needle and other types of waste is visible? } \\
\hline Agree & 279 & 77.3 \\
\hline Disagree & 82 & 22.7 \\
\hline \multicolumn{3}{|c|}{ Do you think using biohazard material better for waste management? } \\
\hline Agree & 251 & 69.5 \\
\hline Disagree & 110 & 30.5 \\
\hline \multicolumn{3}{|c|}{ Do you think that a patient's awareness about the transmission of microorganisms decreases the risk of HCAIs? } \\
\hline Agree & 248 & 68.7 \\
\hline Disagree & 113 & 31.3 \\
\hline \multicolumn{3}{|c|}{ Do you agree that recapping is the cause of needle prick injury? } \\
\hline Agree & 227 & 62.9 \\
\hline Disagree & 134 & 37.1 \\
\hline \multicolumn{3}{|c|}{ Do you believe that nosocomial infection can pose a serious outcome? } \\
\hline Agree & 231 & 64.0 \\
\hline Disagree & 130 & 36.0 \\
\hline
\end{tabular}

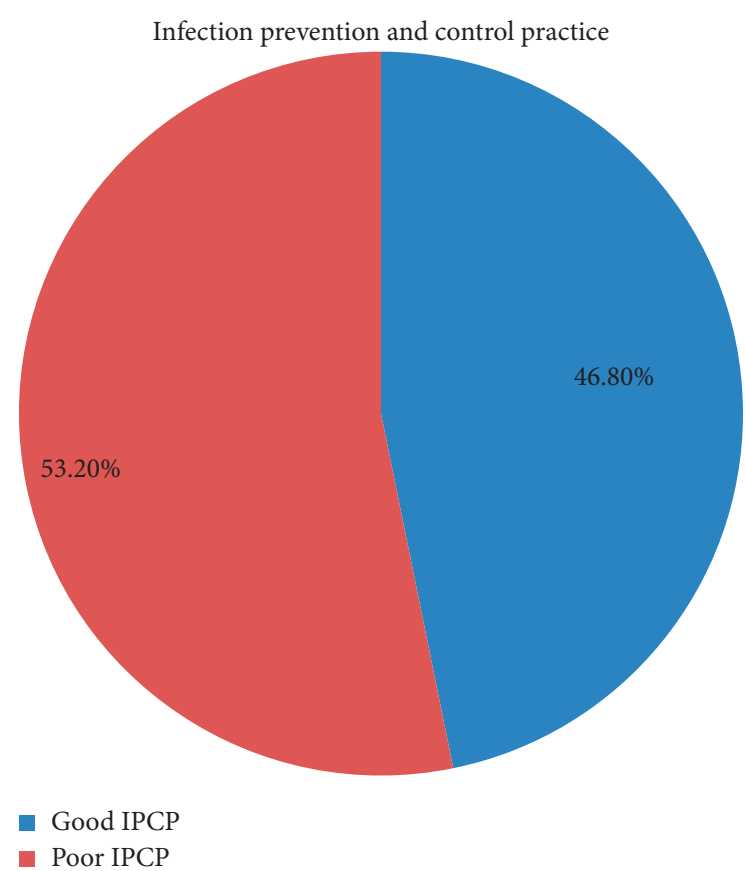

FIgURE 3: The prevalence of infection prevention and control practices among the HWF in NSHCFs environment, Oromiya region, Ethiopia, from January to February $2019(n=361)$.
We found that the positive attitude toward infection prevention and control practice was $59.3 \%$, which is in line with the study done in Bahir Dar city health institutions found that $55.6 \%$ of healthcare workers had reported a good attitude toward infection prevention and control practice [36]. This finding is higher than the study finding from Zabol Teaching Hospital, which revealed that $33 \%$ of HCWs had reported a good attitude toward infection prevention and control practice [38]. On the other hand, this finding is lower than that of the study conducted in Wolaita Sodo (93.4\%) [13]. This difference may be due to variation in awareness of healthcare workers and study settings.

Our study found greater than half (52.6\%) of study participants confirmed to be deficient in an active infection control committee in health facilities. Effective implementation of an infection prevention committee with the standardized guideline policy that emphasizes standard precautions' rational use may help check overtime infection prevention and control practice [39].

Providing on-job training and equipping the skill gap through training and knowledge transfer among healthcare providers and on-time assessment are the effective methods of practicing a safe and clean healthcare environment [40]. We found that only $27.1 \%, 37.1 \%$, and $23.5 \%$ of the health workforce had received training on safe injection, hand washing, and waste segregation, 
TABLE 5: Factors (crude and adjusted odds ratios and confidence intervals) associated with good infection prevention and control practice among the HWF in NSHCFs environment, Oromiya region, Ethiopia, from January to February $2019(n=361)$.

\begin{tabular}{|c|c|c|c|c|c|c|}
\hline Variables & $\begin{array}{c}\text { Infection prevention and } \\
\text { control practice } \\
\text { Poor }\end{array}$ & $\begin{array}{c}\text { Infection prevention } \\
\text { and } \\
\text { control practice } \\
\text { Good }\end{array}$ & $\begin{array}{l}\text { Crude OR }(95 \% \\
\text { CI })\end{array}$ & $p$ value & $\begin{array}{l}\text { Adjusted OR }(95 \% \\
\text { CI) }\end{array}$ & $p$ value \\
\hline \multicolumn{7}{|l|}{ Sex } \\
\hline Male & 145 & 99 & 1 & & 1 & \\
\hline Female & 47 & 70 & $2.20[1.39,3.42]$ & $0.001^{* *}$ & $3.87[1.91,7.86]$ & $0.001^{* *}$ \\
\hline \multicolumn{7}{|l|}{ Age } \\
\hline $20-29$ & 108 & 123 & $2.08[1.33,3.24]$ & $0.001^{* *}$ & $4.08[1.97,8.49]$ & $0.001^{* *}$ \\
\hline $30-42$ & 84 & 46 & 1 & & 1 & \\
\hline \multicolumn{7}{|l|}{ Marital status } \\
\hline Single & 59 & 72 & $1.7[1.08,2.58]$ & $0.020^{*}$ & $3.89[1.92,7.87]$ & $0.001^{* *}$ \\
\hline Married & 133 & 97 & 1 & & 1 & \\
\hline \multicolumn{7}{|l|}{ Profession } \\
\hline Nurse & 99 & 60 & $0.22(0.11,0.46]$ & $0.001^{* *}$ & $0.02[0.01,0.07]$ & $0.001^{* *}$ \\
\hline Physician & 21 & 34 & $0.59[0.25,1.39]$ & 0.225 & $0.43[0.14,1.35]$ & 0.147 \\
\hline Midwives & 19 & 24 & $0.46[0.19,0.40]$ & $0.048^{*}$ & $0.04[0.11,0.15]$ & $0.001^{* *}$ \\
\hline $\begin{array}{l}\text { Medical laboratory } \\
\text { science }\end{array}$ & 41 & 18 & $0.16[0.07,0.38]$ & $0.001^{* *}$ & $0.05[0.02,0.17]$ & $0.001^{* *}$ \\
\hline $\begin{array}{l}\text { Health officers and } \\
\text { others }\end{array}$ & 12 & 33 & 1 & & 1 & \\
\hline \multicolumn{7}{|l|}{ Year of experiences } \\
\hline$<5$ & 118 & 92 & 1 & & 1 & \\
\hline $5-9$ & 53 & 54 & $1.31[0.82,2.08]$ & 0.261 & $0.90[0.43,1.87]$ & 0.776 \\
\hline$\geq 10$ & 21 & 23 & $1.41[1.73,3.69]$ & $0.043^{*}$ & $3.10[1.19,8.10]$ & $0.021^{*}$ \\
\hline \multicolumn{7}{|l|}{ Educational status } \\
\hline Diploma & 30 & 53 & 1 & & 1 & \\
\hline $\mathrm{BSc} / \mathrm{MD}$ & 141 & 108 & $0.43[0.26,0.72]$ & $0.001^{* *}$ & $0.13[0.55,0.30]$ & $0.001^{* *}$ \\
\hline MSc & 21 & 8 & $0.22[0.09,0.55]$ & $0.001^{* *}$ & $0.02[0.01,0.10]$ & $0.001^{* *}$ \\
\hline \multicolumn{7}{|l|}{ Knowledge } \\
\hline Poor & 101 & 59 & 1 & & 1 & \\
\hline Good & 91 & 110 & $2.07[1.35,3.16]$ & $0.001^{* *}$ & $1.10[0.56,2.17]$ & 0.775 \\
\hline \multicolumn{7}{|l|}{ Attitude } \\
\hline Negative & 106 & 41 & 1 & & 1 & \\
\hline Positive & 86 & 128 & $3.85[2.45,6.05]$ & $0.001^{* *}$ & $10.07[4.82,21.05]$ & $0.001^{* *}$ \\
\hline \multicolumn{7}{|l|}{ Aware HW guidelines } \\
\hline No & 68 & 50 & 1 & & 1 & \\
\hline Yes & 124 & 119 & $1.31[0.84,2.03]$ & 0.239 & $1.46[0.78,2.74]$ & 0.243 \\
\hline \multicolumn{7}{|c|}{ Water in the working area } \\
\hline No & 147 & 101 & 1 & & 1 & \\
\hline Yes & 45 & 68 & $2.20[1.40,3.46]$ & $0.001^{* *}$ & $2.27[1.18,4.35]$ & $0.014^{*}$ \\
\hline \multicolumn{7}{|l|}{ Dustbins accessible } \\
\hline No & 97 & 65 & 1 & & 1 & \\
\hline Yes & 95 & 104 & $1.63[1.07,2.48]$ & $0.022^{*}$ & $1.44[0.76,2.66]$ & 0.250 \\
\hline \multicolumn{7}{|l|}{ Training injection safety } \\
\hline No & 152 & 111 & 1 & & 1 & \\
\hline Yes & 40 & 58 & $1.98[1.24,3.18]$ & $0.004^{*}$ & $1.96[0.90,4.25]$ & 0.090 \\
\hline
\end{tabular}

${ }^{*}$ Significant association $(p$ value $<0.05),{ }^{* *} p$ value $\leq 0.001$. HW: hand washing.

respectively. A WHO evidence-based study recommended that trained healthcare providers significantly reduce HCAIs and improve their behavior and perception of infection prevention and control practice [41]. It is also enhancing the healthcare providers' knowledge, effective use of prepared guidelines, and safety precaution to save their staff, patients, and visitor in the healthcare environment [42].
In this study, we found a significant difference in infection prevention among different health facilities that affected the practices; females were more likely than males to practice infection prevention. This finding is similar to the studies done in Mekelle, Gondar, and Wolaita Sodo $[13,32,43]$. A study documented that females had willing to follow infection prevention and control guidelines, safety measures, and a desire to deliver good patient care [44]. 
On the other hand, young participants had a good infection prevention practice compared with those old ones. It is also similar to a study conducted in Mekelle [32], contradicting results reported in Debre Markos, where older ages are more likely to practice infection prevention [33]. This difference might be due to the age category cut point differences or the strength of study design.

The current study revealed a significant statistical association between being a nurse, midwife, and a medical laboratory. This finding is similar to the studies done in Addis Ababa and Mekelle where medical laboratory sciences and nurses were significantly associated with infection prevention and control practice [32, 34]. Nursing, midwifery, and medical laboratory professionals have a higher susceptibility to HCAIs as their working environment is more prone to infection. As a result, they use precaution measures and follow infection prevention and control guidelines, proper use of personal protective equipment, and accurate waste management.

There is also a significant statistical association in the health workforce with greater than ten years of work experience. This result is similar to the studies done in Bahir Dar city [36] and Debre Markos [33]. This may be explained due to increasing work experience; the healthcare providers learn from their previous errors experienced to adhere to infection prevention and control guidelines that may be beneficial for preventing and controlling HCAIs.

Education is a method of equipping the health workforce with up-to-date knowledge and skill of infection prevention and control practice with confidence utilization of recommended guidelines and the available supply [33]. As the educational level was increased, we found that infection prevention and control practices were better than the health workforce, which has a low educational level. This finding is similar to the study result in Debre Markos [33] but contradicts findings from a study done in the Amhara region [35]. The difference might be due to the self-reporting questionnaire and difference in the study area.

Our study also indicated that those who had a positive attitude toward infection prevention and control practices were significantly associated with good infection prevention and control practices. This finding is supported by a study reported from Addis Ababa [34]. The individual positive attitudes and beliefs may reflect healthcare workers' perception of the value of infection prevention and control guidelines in protecting them, their families, and their patients [45].

In this study, we found that $66.6 \%$ of the health centers and $69.3 \%$ of the hospitals had no running water in the healthcare facilities. However, only $31.3 \%$ of healthcare facilities have adequate running waters, which are statistically significant associated with infection prevention and control practices. This indicates that having running water in healthcare facilities is vital for infection prevention and control practices, which is useful for hand hygiene, equipment disinfected, and quality healthcare delivery. A previous study indicates that water provision in the healthcare setting is indispensable for clean procedure and survival of patient life; it plays an essential role in protecting human health from healthcare-associated infections [46].

\section{Limitation of the study}

This study has limitations; first, it does not show a causal relationship due to its cross-sectional nature. Second, the study has been conducted at healthcare facilities located only in the North Showa Zone healthcare facilities, the Oromiya region. Hence, our findings cannot be generalizable to the other regions of Ethiopia.

\section{Conclusions}

In this study, many health workers had low knowledge, negative attitudes, and poor infection prevention practices. Female participants, higher work experience, a positive attitude, and water availability in the healthcare facilities were positively associated with infection prevention and control practice. Effective performance is required to deliver safe and clean healthcare facilities for optimal outcomes, for both patients and healthcare providers. Healthcare facilities should be continued capacitating the health workforce on infection prevention and control measures and equipping health facilities with infection prevention materials. The Ethiopian Federal Ministry of Health should make an effort to promote clean and safe clinical practice following guidelines, optimizing the healthcare environment to ensure a working system that supports the effective implementation of infection prevention and control practices.

\section{Abbreviations}

CASH: Clean and safe health facility

HCFs: Healthcare facilities

HCWs: Healthcare workers

HWF: Health workforce

IPCP: Infection prevention control practice

NSHCFs: North Shoa healthcare facilities

SPSS: $\quad$ Statistical package for social sciences

WHO: World Health Organization.

\section{Data Availability}

The datasets used and/or analyzed during the current study are available from the corresponding author upon reasonable request.

\section{Ethical Approval}

Ethical clearance was obtained from the Salale University Ethical Review Committee. Written permission was obtained from the North Showa Zonal Health Bureau and each healthcare facility.

\section{Consent}

Written informed consent was obtained from all study participants.

\section{Disclosure}

To ensure the confidentiality of respondents, their names were excluded from the questionnaire. 


\section{Conflicts of Interest}

The authors declare that they have no conflicts of interest.

\section{Authors' Contributions}

$\mathrm{KJ}, \mathrm{KG}$, and TK conceived the study, were involved in the study design, analysis, and report writing, reviewed the article, and drafted the manuscript. WB and BG were involved in the study design and report writing and drafted the manuscript. All the authors read and approved the final manuscript.

\section{Acknowledgments}

The authors acknowledge the Canadian Physicians for Aid and Relief for funding this research and all health workforces for their genuine participation.

\section{References}

[1] P. E. Petersen, "World health organization global policy for improvement of oral health-World health assembly 2007," International Dental Journal, vol. 58, no. 3, pp. 115-121, 2008.

[2] B. Allegranzi, S. B. Nejad, C. Combescure et al., "Burden of endemic health-care-associated infection in developing countries: systematic review and meta-analysis," The Lancet, vol. 377, no. 9761, pp. 228-241, 2011.

[3] S. Nelson, P. W. Stone, S. Jordan et al., "Patient safety climate: variation in perceptions by infection preventionists and quality directors," Interdisciplinary Perspectives on Infectious Diseases, vol. 2011, Article ID 357121, 7 pages, 2011.

[4] World health organization (WHO), Infection Prevention and Control in Health Care: Time for Collaborative Action: Regional Committee for the Eastern Mediterranean, WHO, Geneva, Switzerland, 2010, http://www.emro.who.int/Em_ RC57_4_en.pdf.

[5] L. Tietjen, D. Bossemeyer, and N. McIntosh, Infection Prevention: Guidelines for Healthcare Facilities with Limited Resources, JHPIEGO Corporation, Baltimore, MA, USA, 2003.

[6] R. M. Klevens, J. R. Edwards, C. L. Richards et al., "Estimating health care-associated infections and deaths in US hospitals," Public Health Reports, vol. 122, no. 2, pp. 160-166, 2002.

[7] R. D. Scott, The Direct Medical Costs of Healthcare-Associated Infections in US Hospitals and the Benefits of Prevention Division of Healthcare Quality Promotion, National Center for Preparedness, Detection, and Control of Infectious Diseases, Coordinating Center for Infectious Diseases, Centers for Disease Control and Prevention, D. A. Polock and P. W. Stone, Eds., Economist, London, UK, 2009.

[8] J. V. Bennett, W. R. Jarvis, and P. S. Brachman, Bennett \& Brachman's Hospital Infections, Lippincott Williams \& Wilkins, Philadelphia, PA, US, 2007.

[9] D. Ogoina, K. Pondei, B. Adetunji, G. Chima, C. Isichei, and S. Gidado, "Knowledge, attitude and practice of standard precautions of infection control by hospital workers in two tertiary hospitals in Nigeria," Journal of Infection Prevention, vol. 16, no. 1, pp. 16-22, 2015.

[10] M. Gertrude, Factors Influencing Compliance with Infection Prevention Standard Precautions Among Nurses Working at Mbagathi District Hospital, Nairobi, Kenya, University of Nairobi, Nairobi, Kenya, 2013.
[11] K. Gulilat and G. Tiruneh, "Assessment of knowledge, attitude and practice of health care workers on infection prevention in health institution Bahir Dar city administration," Science Journal of Public Health, vol. 2, no. 5, pp. 384-393, 2014.

[12] B. Sahiledengle, A. Gebresilassie, T. Getahun, and D. Hiko, "Infection prevention practices and associated factors among healthcare workers in governmental healthcare facilities in Addis Ababa," Ethiopian Journal of Health Sciences, vol. 28, no. 2, pp. 177-186, 2018.

[13] S. Hussein, W. Estifanos, E. Melese, and F. Moga, "Knowledge, attitude and practice of infection prevention measures among health care workers in Wolaitta Sodo Otona teaching and referral hospital," Journal of Nursing Care, vol. 6, no. 416, pp. 2167-1168, 2017.

[14] S. Accorsi, N. K. Bilal, P. Farese, and V. Racalbuto, "Countdown to 2015: comparing progress towards the achievement of the health millennium development goals in Ethiopia and other sub-Saharan African countries," Transactions of the Royal Society of Tropical Medicine and Hygiene, vol. 104, no. 5, pp. 336-342, 2010.

[15] T. Shimelis, K. Lemma, H. Ambachew, and E. Tadesse, "Syphilis among people with HIV infection in southern Ethiopia: sero-prevalence and risk factors," BMC Infectious Diseases, vol. 15, no. 1, p. 189, 2015.

[16] G. Gebrekidan, G. Tesfaye, M. T. Hambisa, and N. Deyessa, "Quality of tuberculosis care in private health facilities of Addis Ababa, Ethiopia," Tuberculosis Research and Treatment, vol. 2014, Article ID 720432, 9 pages, 2014.

[17] J. Musau, A. Baumann, C. Kolotylo, T. O'shea, and A. Bialachowski, "Infectious disease outbreaks and increased complexity of care," International Nursing Review, vol. 62, no. 3, pp. 404-411, 2015.

[18] J. Adams, J. Bartram, and Y. Chartier, Essential Environmental Health Standards in Health Care, World Health Organization, Geneva, Switzerland, 2008.

[19] Z. A. Memish, A. Zumla, R. F. Alhakeem et al., "Hajj: infectious disease surveillance and control," The Lancet, vol. 383, no. 9934, pp. 2073-2082, 2014.

[20] W. Zingg, A. Holmes, M. Dettenkofer et al., "Hospital organisation, management, and structure for prevention of health-care-associated infection: a systematic review and expert consensus," The Lancet Infectious Diseases, vol. 15, no. 2, pp. 212-224, 2015.

[21] B. Hollis and R. Verma, The Intersection of Hospitality and Healthcare: Exploring Common Areas of Service Quality, Human Resources, and Marketing, Cornell University, New York, NY, USA, 2015.

[22] C. A. Leibrock and D. D. Harris, Design Details for Health: Making the Most of Design's Healing Potential, John Wiley \& Sons, Hoboken, NJ, US, 2011.

[23] J. Conway, B. Johnson, S. Edgman-Levitan et al., Partnering with Patients and Families to Design a Patient-And FamilyCentered Health Care System: A Roadmap for the Future: a Work in Progress, Institute for Family-Centered Care, Bethesda, MD, USA, 2006.

[24] K. Dijkstra, M. Pieterse, and A. Pruyn, "Physical environmental stimuli that turn healthcare facilities into healing environments through psychologically mediated effects: systematic review," Journal of Advanced Nursing, vol. 56, no. 2, pp. 166-181, 2006.

[25] M. Kagawa-Singer and S. Kassim-Lakha, "A strategy to reduce cross-cultural miscommunication and increase the likelihood of improving health outcomes," Academic Medicine, vol. 78, no. 6, pp. 577-587, 2003. 
[26] Y. Seman, Clean and Safe Health Facility Initiative(CASH) in Ethiopia, WHO, Geneva, Switzerland, 2016.

[27] B. S. Geberemariyam, G. M. Donka, and B. Wordofa, "Assessment of knowledge and practices of healthcare workers towards infection prevention and associated factors in healthcare facilities of West Arsi district, Southeast Ethiopia: a facility-based cross-sectional study," Archives of Public Health, vol. 76, no. 1, p. 69, 2018.

[28] World Health Organization, Infection Prevention and Control Assessment Framework at the Facility Level, World Health Organization, Geneva, Switzerland, 2018.

[29] Clean and Safe Health Care Facilities, http://www. qualityofcarenetwork.org/knowledge-library/clean-and-safehealth-facilities-cash-audit-tool, 2016.

[30] A. Muluken, G. Haimanot, and M. Mesafint, "Healthcare waste management practices among healthcare workers in healthcare facilities of Gondar town, Northwest Ethiopia," Health Science Journal, vol. 7, no. 3, 2014.

[31] M. A. Yenesew, H. G. Moges, and S. M. Woldeyohannes, “A cross sectional study on factors associated with risk perception of healthcare workers toward healthcare waste management in health care facilities of Gondar town, Northwest Ethiopia," International Journal of Infection Control, vol. 8, no. 3, pp. 1-9, 2012.

[32] A. Gebresilassie, A. Kumei, and D. Yemane, "Standard precautions practice among health care workers in public health facilities of Mekelle special zone, Northern Ethiopia," Journal of Community Medicine \& Health Education, vol. 4, no. 3, p. 286, 2014.

[33] M. Desta, T. Ayenew, N. Sitotaw, N. Tegegne, M. Dires, and M. Getie, "Knowledge, practice and associated factors of infection prevention among healthcare workers in Debre Markos referral hospital, Northwest Ethiopia," BMC Health Services Research, vol. 18, no. 1, p. 465, 2018.

[34] B. S. Gebremariyam, "Determinants of occupational exposure to blood and body fluids, healthcare workers' risk perceptions and standard precautionary practices: a hospital-based study in Addis Ababa, Ethiopia," Ethiopian Journal of Health Development, vol. 33, no. 1, 2019.

[35] F. A. Teshager, E. H. Engeda, and W. Z. Worku, "Knowledge, practice, and associated factors towards prevention of surgical site infection among nurses working in Amhara regional state referral hospitals, Northwest Ethiopia," Surgery Research and Practice, vol. 2015, Article ID 736175, 6 pages, 2015.

[36] G. G. T. Kelemua, "Assessment of knowledge, attitude and practice of health care workers on infection prevention in health institution Bahir dar city administration," Science Journal of Public Health, vol. 2, no. 5, pp. 384-393, 2014.

[37] R. Alemayehu, K. Ahmed, and O. Sada, "Assessment of knowledge and practice on infection prevention among health care workers at Dessie referral hospital, Amhara region, SouthWollo zone, North East Ethiopia," Journal of Community Medicine \& Health Education, vol. 6, no. 487, pp. 2161-0711, 2016.

[38] H. Sarani, A. Balouchi, N. Masinaeinezhad, and E. Ebrahimitabs, "Knowledge, attitude and practice of nurses about standard precautions for hospital-acquired infection in teaching hospitals affiliated to Zabol university of medical sciences," Global Journal of Health Science, vol. 8, no. 3, p. 193, 2014.

[39] Y. Chartier, Safe Management of Wastes from Health-Care Activities, World Health Organization, Geneva, Switzerland, 2014.
[40] World Health Organization, Global Action Plan on Antimicrobial Resistance, World Health Organization, Geneva, Switzerland, 2015.

[41] J. Storr, A. Twyman, W. Zingg et al., "Core components for effective infection prevention and control programmes: new WHO evidence-based recommendations," Antimicrobial Resistance \& Infection Control, vol. 6, no. 1, p. 6, 2017.

[42] C. Houghton, P. Meskell, H. Delaney et al., "Barriers and facilitators to healthcare workers' adherence with infection prevention and control (IPC) guidelines for respiratory infectious diseases: a rapid qualitative evidence synthesis," Cochrane Database of Systematic Reviews, vol. 4, no. 4, 2020.

[43] T. G. Haile, E. H. Engeda, and A. A. Abdo, "Compliance with standard precautions and associated factors among healthcare workers in gondar university comprehensive specialized hospital, Northwest Ethiopia," Journal of Environmental and Public Health, vol. 2017, Article ID 2050635, 8 pages, 2017.

[44] E. L. Wong, S. Y. Wong, N. Lee, A. Cheung, and S. Griffiths, "Healthcare workers' duty concerns of working in the isolation ward during the novel H1N1 pandemic," Journal of Clinical Nursing, vol. 21, no. 9-10, pp. 1466-1475, 2012.

[45] F. Zinatsa, M. Engelbrecht, A. J. van Rensburg, and G. Kigozi, "Voices from the frontline: barriers and strategies to improve tuberculosis infection control in primary health care facilities in South Africa," BMC Health Services Research, vol. 18, no. 1, p. 269, 2018.

[46] D. Harris and M. Kolly, Political Economy Analysis for Water, Sanitation and Hygiene (WASH) Service Delivery, Overseas Development Institute, London, UK, 2012. 